\title{
KOMPRES HANGAT MEMPENGARUHI DERAJAT NYERI MENSTRUASI PADA SISWI KELAS X DI SMA NEGERI 2 PAMEKASAN
}

\author{
Makrifatul Amaliyah $^{1}$, R. Khairiyatul Afiyah ${ }^{2}$ \\ Prodi Ners, Fakultas Keperawatan dan Kebidanan Universitas NU Surabaya \\ E-mail:Satu_37@yahoo.co.id
}

\begin{abstract}
Abstrak
Nyeri menstruasi dapat menyebabkan gangguan aktivitas sehari-hari. Salah satu cara penanganan untuk mengurangi derajat nyeri menstruasi dengan melakukan kompres hangat. Angka kejadian nyeri menstruasi di SMAN 2 Pamekasan, $70 \%$ siswi kelas $\mathrm{X}$ mengalami nyeri menstruasi. Penelitian ini bertujuan mengetahui hubungan kompres hangat terhadap derajat nyeri menstruasi pada siswi kelas X di SMA Negeri Pamekasan.

Desain penelitian ini adalah analitik dengan rancang bangun cross sectional. Populasi adalah siswi kelas X yang mengalami nyeri menstruasi pada hari $1-3$ dan tidak mengkonsumsi obat anti nyeri. Sampel sebanyak 88 responden, sampling simple random sampling. Instrumen menggunakan lembar observasi. Data yang diperoleh diolah dengan SPSS for windows diuji dengan MannWhitney dengan tingkat kemaknaan $\alpha=0,005$.

Hasil penelitian menunjukkan dari 88 responden, sebagian besar $(64,8 \%)$ responden melakukan kompres hangat, sebagian besar $(63,6 \%)$ responden mengalami derajat nyeri menstruasi ringan. Hasil uji Mann-Whitney diperoleh $\mathrm{p}=0,024$ dan $\alpha=0,05$, berarti $\rho<\alpha$ maka $\mathrm{H}_{0}$ ditolak artinya ada hubungan kompres hangat terhadap derajat nyeri menstruasi pada siswi kelas $\mathrm{X}$ di SMA Negeri 2 Pamekasan.
\end{abstract}

Kompres hangat dapat mengurangi derajat nyeri menstruasi. Diharapkan bagi siswi untuk menangani nyeri menstruasi dengan melakukan kompres hangat.

Kata Kunci: kompres hangat, derajat nyeri menstruasi

\begin{abstract}
The pain of menstruation can cause a nuisance of daily activity. One of the handling way to reduce the level of menstruation pain is doing warm compress. The event rate of menstruation pain in SMAN 2 Pamekasan, 70\% female students of tenth grade get the menstruation pain. The research intends to know the relation of warm compress to the level of menstruation pain to female students of tenth grade in SMAN 2 Pamekasan.

The design of research is analytic with the construction design of cross sectional, the population is female students of tenth grade who get the menstruation pain on the first until the third day and they don't take a medicine, which can reduce of the pain. The sample is 88 respondents, sampling simple random sampling. The date that are gotten, are processed with SPSS for windows and are examined by Mann-Whitney with the meaning level $\alpha=0,005$.

The result of research shows that 88 respondents, the most of 57 respondents who did the warm compress, get the minor of menstruation pain is 31 respondents $(54,4 \%)$, and 31 respondents who did the usual compress, almost all of them get the minor of menstruation pain, is 25 respondents
\end{abstract}


(80,6\%), the test research of Mann-Whitney is gotten $p=0,024$ and $\alpha=0,05$, it means that $\rho<\alpha$ so $\mathrm{H}_{0}$ is refused, means that there is correlation between the warm compress to the level of menstruation pain to female students of tenth grade in SMAN 2 Pamekasan.

The warm compress reduce the menstruation pain. I hope that the female students handle the menstruation pain by doing warm compress.

Keywords : warm compress, level of menstruation pain

\section{Pendahuluan}

Masa remaja atau masa pubertas merupakan masa penghubung antara masa anak-anak dengan masa dewasa. Pertumbuhan dan perkembangan pada masa remaja sangat pesat, baik fisik maupun psikologis. Perkembangan yang pesat ini berlangsung pada usia $10-15$ tahun pada perempuan. Salah satu ciri masa pubertas yaitu mulai terjadinya menstruasi. Menstruasi adalah perdarahan secara periodik dan siklik dari uterus, disertai pelepasan (deskuamasi) endometrium. Proses terjadinya menstruasi berlangsung dengan empat tahapan yaitu masa proliferasi, ovulasi, sekresi, dan menstruasi. Pada kenyataannya banyak perempuan yang mengalami masalah menstruasi, yaitu nyeri menstruasi atau dismenore (Proverawati \& Misaroh, 2009).

Nyeri menstruasi atau dismenore merupakan kram dan nyeri menusuk yang terasa di perut bagian bawah dan paha, punggung bawah, yang disertai mual muntah, diare, selama menstruasi, lemah, dan berkeringat. Nyeri menstruasi sering membuat perempuan menjadi tidak nyaman.

Di Indonesia angka kejadian nyeri menstruasi sebesar $64,25 \%$. Nyeri menstruasi ada dua jenis yaitu nyeri menstruasi primer dan nyeri menstruasi sekunder. Nyeri menstruasi primer dimulai saat $2-3$ tahun setelah menarche dan mencapai maksimalnya pada usia 15 - 25 tahun (Hendrik, 2006). Angka kejadian sebesar 54,89\% nyeri menstruasi primer dan $9,36 \%$ nyeri menstruasi sekunder dari $64,25 \%$ kejadian nyeri menstruasi. Di Surabaya didapatkan $1,07 \%-1,31 \%$ dari jumlah penderita nyeri menstruasi datang ke bagian kebidanan (Harunriyanto, 2008). Berdasarkan hasil survey dengan cara wawancara tentang nyeri menstruasi yang dilakukan oleh peneliti pada bulan November 2012 pada siswi kelas X di SMA Negeri 2 Pamekasan yang berjumlah 160 siswi, peneliti mengambil 10 siswi yang mewakili seluruh siswi, dari 10 siswi tersebut mengatakan dalam menangani nyeri menstruasi didapatkan 7 siswi (70\%) menggunakan obat analgesik, 3 siswi (30\%) tidak menggunakan obat-obatan.

Saat menjelang menstruasi tubuh wanita menghasilkan suatu zat yang disebut prostaglandin. Zat tersebut mempunyai fungsi yang salah satunya adalah membuat dinding rahim berkontraksi dan pembuluh darah sekitarnya terjepit (konstriksi) yang menimbulkan iskemi jaringan. Intensitas kontraksi ini berbeda-beda setiap individu dan apabila berlebihan akan menimbulkan nyeri menstruasi. Nyeri menstruasi yang dialami saat menstruasi bisa sangat menyiksa. Kadangkadang perempuan membungkukkan tubuh atau merangkak lantaran tidak mampu menahan rasa nyeri bahkan ada yang sampai berguling-guling di tempat tidur. Hal ini sangat mengganggu aktivitas perempuan sehari-hari dan dapat berdampak pada turunnya produktivitas kerja, gangguan aktivitas hidup sehari-hari (ADLs), dan terjadi gangguan sistem reproduksi seperti retrograd menstruasi (menstruasi yang bergerak mundur), infertilitas (kemandulan), kehamilan atau kehamilan tidak terdeteksi ektopik pecah, kista pecah, perforasi rahim dari IUD dan infeksi (Andre, 2009). Selain dari dampak 
diatas, konflik emosional, ketegangan dan kegelisahan dapat memainkan peranan serta menimbulkan perasaan yang tidak nyaman. Oleh karena itu nyeri menstruasi pada semua usia harus ditangani agar tidak terjadi masalah seperti hal- hal tersebut (Knight, 2006).

Cara mengurangi nyeri menstruasi terdapat dua tindakan yaitu secara farmakologis dan non farmakologis. Salah satu intervensi keperawatan untuk menurunkan nyeri adalah kompres hangat, yaitu memberikan rasa hangat pada daerah tertentu dengan menggunakan kantung berisi air hangat yang menimbulkan rasa hangat pada bagian tubuh yang memerlukan. Kompres hangat dengan suhu $45^{\circ} \mathrm{C}-50,5^{\circ} \mathrm{C}$ dapat dilakukan dengan menempelkan kantung karet yang diisi air hangat ke daerah tubuh yang nyeri. Tujuan dari kompres hangat adalah pelunakan jaringan fibrosa, membuat otot tubuh lebih rileks, menurunkan rasa nyeri, dan mempelancar pasokan aliran darah dan memberikan ketenangan pada klien (Kimin, 2009). Mengingat pentingnya masalah di atas, penulis tertarik untuk melakukan penelitian tentang "Hubungan kompres hangat terhadap derajat nyeri menstruasi pada siswi kelas $\mathrm{X}$ di SMA Negeri 2 Pamekasan".

\section{Metode Penelitian}

Dalam penelitian ini jenis yang digunakan adalah analitik dengan desain cross sectional. Populasi dalam penelitian ini adalah siswi kelas $\mathrm{X}$ yang mengalami nyeri menstruasi pada hari pertama sampai hari ketiga dan tidak minum obat anti nyeri di SMA Negeri 2 Pamekasan, sebesar 112 siswi. Sampel dalam penelitian ini adalah sebagian siswi kelas $X$ yang mengalami nyeri menstruasi pada hari pertama sampai hari ketiga dan tidak minum obat anti nyeri di SMA Negeri 2 Pamekasan sebesar 88 responden.

Cara pengambilan sampel dalam penelitian ini menggunakan teknik probality sampling secara simple random sampling, yaitu pengambilan sampel secara acak dari seluruh siswi yang mengalami nyeri menstruasi, dimana setiap anggota populasi mempunyai kesempatan yang sama untuk diseleksi.

Instrumen yang digunakan peneliti dalam penelitian ini adalah buli-buli dan sarungnya, dan lembar observasi.

\section{Hasil dan Pembahasan, Kesimpulan}

Hasil Data khusus berisi karakteristik responden yang meliputi kompres, nyeri menstruasi, dan hubungan kompres dengan nyeri menstruasi.

Tabel 5.1 Distribusi frekuensi responden berdasarkan kompres siswi di SMA Negeri 2 Pamekasan bulan Maret 2013

\begin{tabular}{clcc}
\hline No. & Kompres & Frekuensi & Persentase(\%) \\
\hline 1 & Kompres & 57 & 64,8 \\
2 & hangat & 31 & 35,2 \\
& $\begin{array}{l}\text { Kompres } \\
\text { air biasa }\end{array}$ & & \\
\hline \multicolumn{2}{c}{ Jumlah } & 88 & 100
\end{tabular}

Sumber : Data primer, Maret 2013

Berdasarkan tabel 5.5 dapat diketahui dari 88 responden sebagian besar (64,8\%) menggunakan kompres hangat.

Tabel 5.2 Distribusi frekuensi responden berdasarkan derajat nyeri menstruasi siswi di SMA Negeri 2 Pamekasan bulan Maret 2013

\begin{tabular}{cccc}
\hline No. & $\begin{array}{c}\text { Derajat } \\
\text { Nyeri } \\
\text { Menstruasi }\end{array}$ & Frekuensi & Persentase(\%) \\
\hline 1 & Ringan & 56 & 63,6 \\
2 & Sedang & 26 & 29,5 \\
3 & Berat & 6 & 6,8 \\
\hline & Jumlah & 88 & 100 \\
\hline
\end{tabular}

Sumber : Data primer, Maret 2013

Berdasarkan tabel 5.6 dapat diketahui dari 88 responden sebagian besar $(63,6 \%)$ mengalami derajat nyeri menstruasi ringan.

\section{a. Tabulasi Silang}

Hubungan kompres hangat terhadap derajat nyeri menstruasi pada siswi kelas X di SMA Negeri 2 Pamekasan untuk bisa diketahui, 
maka menggunakan tabulasi silang (cross tabulation) dan didapatkan seperti pada tabel 5.3:

Tabel 5.3 Tabulasi silang kompres hangat terhadap derajat nyeri menstruasi pada siswi kelas X di SMA Negeri 2 Pamekasan bulan Maret 2013.

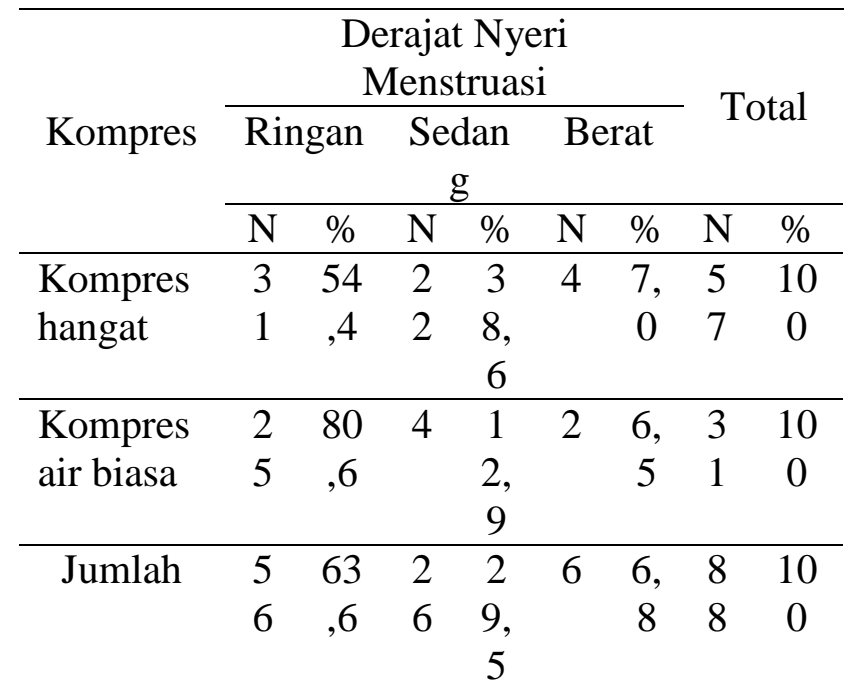

Sumber : Data primer, Maret 2013

Berdasarkan tabel 5.7 di atas menunjukkan bahwa dari 57 responden yang melakukan kompres hangat sebagian besar $(54,4 \%)$ mengalami derajat nyeri menstruasi ringan, sedangkan dari 31 responden yang melakukan kompres air biasa hampir seluruhnya $(80,6 \%)$ mengalami derajat nyeri menstruasi ringan. Hasil uji statistik dengan menggunakan MannWhitney, didapatkan $p=0,024$ dan $\alpha=0,05$, berarti $\rho<\alpha$ maka $\mathrm{H}_{0}$ ditolak artinya terdapat hubungan kompres hangat terhadap derajat nyeri menstruasi pada siswi kelas $\mathrm{X}$ di SMA Negeri 2 Pamekasan.

Pembahasan Hasil penelitian menunjukkan bahwa kompres hangat dapat mengurangi derajat nyeri menstruasi pada siswi kelas $\mathrm{X}$ di SMA Negeri 2 Pamekasan. Nyeri menstruasi yang dialami siswi sebagian besar nyeri menstruasi ringan. Nyeri menstruasi tersebut sebagian besar terjadi pada siswi berumur 16 tahun, yang umur menstruasi pertamakali berumur 10 - 13 tahun. Sebagian besar siswi tersebut mengalami nyeri menstruasi waktu menstruasi hari ke-2.
Penanganan non farmakologi terhadap nyeri menstruasi salah satunya menggunakan kompres hangat. Kompres hangat dapat menyebabkan jaringan fibrosa menjadi lunak, otot tubuh menjadi rileks, memperlancar aliran darah, dan memberi ketenangan pada klien sehingga bisa menurunkan rasa nyeri. Pemberian kompres hangat pada daerah tubuh akan memberikan sinyal ke hipothalamus melalui sumsum tulang belakang. Ketika reseptor yang peka terhadap panas di hipotalamus dirangsang, sistem effektor mengeluarkan sinyal yang memulai berkeringat dan vasodilatasi perifer. Perubahan ukuran pembuluh darah diatur oleh pusat vasomotor pada medulla oblongata dari tangkai otak, di bawah pengaruh hipotalamik bagian anterior sehingga terjadi vasodilatasi. Terjadinya vasodilatasi ini menyebabkan penurunan nyeri. Nyeri menstruasi pada remaja harus ditangani meskipun hanya dengan pengobatan sendiri atau non farmakalogi untuk menghindari dampak yang lebih berat, seperti gangguan aktivitas hidup sehari-hari (ADLs). Sehingga derajat nyeri menstruasi yang dirasakan responden setelah dilakukan kompres hangat derajat nyeri menstruasi ringan.

Menurut Perry dan Potter (2005) kompres hangat yang dilakukan menyebabkan pelebaran pembuluh darah dan akan terjadi penurunan ketegangan otot sehingga nyeri menstruasi yang dirasakan akan berkurang atau hilang.

Kesimpulan Berdasarkan hasil penelitian yang telah diuraikan, maka dapat dirumuskan simpulan sebagai berikut:

1. Siswi kelas $X$ di SMA Negeri 2 Pamekasan sebagian besar melakukan kompres hangat untuk penanganan nyeri menstruasi.

2. Siswi kelas $X$ di SMA Negeri 2 Pamekasan sebagian besar mengalami derajat nyeri menstruasi ringan.

3. Ada hubungan kompres hangat terhadap derajat nyeri menstruasi pada siswi kelas $\mathrm{X}$ di SMA Negeri 2 Pamekasan. 
Daftar Acuan

Azis, A \& Musrifatul, U (2005). Kebutuhan Dasar Manusia : Buku Saku Praktikum. Jakarta, EGC

Anonim (2009). Gangguan Menstruasi. Http://www.info-sehat.com. artikel diakses pada tanggal 7 Desember 2012.

Anurogo dan Wulandari (2011). Cara Jitu Mengatasi Nyeri Haid. Yogyakarta, ANDI

Arikunto (2006). Prosedur Penelitian Suatu Pendekatan Praktek. Jakarta, Rineka Cipta

Bobak (2004). Buku Ajar Keperawatan Maternitas. Jakarta, EGC

Junizar (2004). Kejadian Dismenorea Primer. Http://journal.unair.ac.id diakses pada tanggal 7 Desember 2012.

Kozier dan Erb's (2009). Buku Ajar Praktik Keperawatan Klinis, Ed 5. Jakarta, EGC

Kozier dan Erb's (2011). Buku Ajar Fundamental Keperawatan:Konsep, Proses, dan Praktik, Ed 7 Vol.2. Jakarta, EGC

Laila, Nur Najmi (2011). Buku Pintar Menstruasi. Yogyakarta, Buku Biru.

Manuaba, IBG. (2008). Gawat-Darurat Obstreti-Ginekologi dan ObstretiGinekologi untuk Profesi Bidan. Jakarta, EGC

Notoatmodjo (2010). Metodelogi Penelitian Kesehatan. Jakarta, Rineka Cipta

Nursalam (2011). Konsep dan Penerapan Metodologi Penelitian Ilmu Keperawatan:Pedoman Skripsi, Tesis dan Instrumen Penelitian Keperawatan. Jakarta, Salemba Medika.

Perry dan Potter (2005). Keterampilan dan Prosedur Dasar. Jakarta, EGC

Purnomo, Windhu (2007). Hand Out/ Metodologi Penelitian Kuantitatif. Surabaya, FKM Unair

Proverawati dan Misaroh (2009). Menarche Menstruasi Pertama Penuh Makna. Yogyakarta, Nuha Medika
Riyanto (2002). Dismenorea.

Http://www.Lampung.com.artikel diakses pada tanggal 7 Desember 2012.

Sarwono, P. (2005). Ilmu Kandungan. Edisi 2 cetakan IV. Jakarta, Yayasan Bina Pustaka.

Sastroasmoro dan Ismael (2008). DasarDasar Metodologi Penelitian Klinis, Ed.3. Jakarta, Sagung Seto

Tamsuri, Anas (2007). Konsep dan Penatalaksanaan Nyeri. Jakarta, EGC

Winkjosastro, Hanifa (2007). Ilmu Kebidanan. Jakarta, YBP-SP (2013). Pedoman Penyusunan dan Prosedur ujian Proposal-Karya Tulis ilmiah-Skripsi Program Studi S1Keperawatan. Surabaya, STIKES YARSI 